\title{
Medicare Reimbursement for Total Joint Arthroplasty: The Driving Forces.
}

\author{
Eric M. Padegimas \\ Thomas Jefferson University \\ Kushagra Verma \\ Thomas Jefferson University \\ Benjamin Zmistowski \\ Thomas Jefferson University \\ Richard H. Rothman \\ Thomas Jefferson University \\ James J. Purtill \\ Thomas Jefferson University \\ Follow this and additional works at: https://jdc.jefferson.edu/orthofp \\ Part of the Orthopedics Commons, and the Surgery Commons

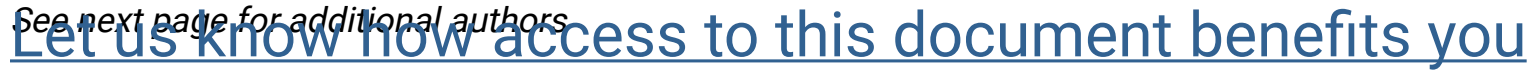

\section{Recommended Citation}

Padegimas, Eric M.; Verma, Kushagra; Zmistowski, Benjamin; Rothman, Richard H.; Purtill, James J.; and Howley, Michael, "Medicare Reimbursement for Total Joint Arthroplasty: The Driving Forces." (2016). Department of Orthopaedic Surgery Faculty Papers. Paper 88.

https://jdc.jefferson.edu/orthofp/88

This Article is brought to you for free and open access by the Jefferson Digital Commons. The Jefferson Digital Commons is a service of Thomas Jefferson University's Center for Teaching and Learning (CTL). The Commons is a showcase for Jefferson books and journals, peer-reviewed scholarly publications, unique historical collections from the University archives, and teaching tools. The Jefferson Digital Commons allows researchers and interested readers anywhere in the world to learn about and keep up to date with Jefferson scholarship. This article has been accepted for inclusion in Department of Orthopaedic Surgery Faculty Papers by an authorized administrator of the Jefferson Digital Commons. For more information, please contact: JeffersonDigitalCommons@jefferson.edu. 


\section{Authors}

Eric M. Padegimas, Kushagra Verma, Benjamin Zmistowski, Richard H. Rothman, James J. Purtill, and Michael Howley 


\title{
Medicare Reimbursement for Total Joint Arthroplasty: The Driving Forces
}

\author{
Eric M. Padegimas, MD, Kushagra Verma, MD, Benjamin Zmistowski, MD, Richard H. Rothman, MD, PhD, \\ James J. Purtill, MD, and Michael Howley, $\mathrm{PhD}$ \\ Investigation performed at The Rothman Institute, Thomas Jefferson University Hospital, Philadelphia, Pennsylvania
}

\begin{abstract}
Background: Total joint arthroplasty is a large and growing part of the U.S. Medicare budget, drawing attention to how much providers are paid for their services. The purpose of this study was to examine the variables that affect total joint arthroplasty reimbursement. Along with standard economic variables, we include unique health-care variables. Given the focus on value in the Affordable Care Act, the model examines the relationship of the quality of care to total joint arthroplasty reimbursement. We hoped to find that reimbursement patterns reward quality and reflect standard economic principles.
\end{abstract}

Methods: Multivariable regression was performed to identify variables that correlate with Medicare reimbursement for total joint arthroplasty. Inpatient charge or reimbursement data on Medicare reimbursements were available for 2,750 hospitals with at least 10 discharges for uncomplicated total joint arthroplasty from the Centers for Medicare \& Medicaid Services (CMS) for fiscal year 2011. Reimbursement variability was examined by using the Dartmouth Atlas to group institutions into hospital referral regions and hospital service areas. Independent variables were taken from the Dartmouth Atlas, CMS, the WWAMI (Washington, Wyoming, Alaska, Montana, Idaho) Rural Health Research Center, and the United States Census.

Results: There were 427,207 total joint arthroplasties identified, with a weighted mean reimbursement of $\$ 14,324.84$ (range, $\$ 9,103$ to $\$ 38,686$ ). Nationally, the coefficient of variation for reimbursements was 0.19 . The regression model accounted for $52.5 \%$ of reimbursement variation among providers. The total joint arthroplasty provider volume $(p<0.001)$ and patient satisfaction $(p<0.001)$ were negatively correlated with reimbursement. Government ownership of a hospital $(p<0.001)$ and higher Medicare costs $(p<0.001)$ correlated positively with reimbursement.

Conclusions: Medicare reimbursements for total joint arthroplasty are highly variable. Greater reimbursement was associated with lower patient volume, lower patient satisfaction, a healthier patient population, and government ownership of a hospital. As value-based reimbursement provisions of the Affordable Care Act are implemented, there will be dramatic changes in total joint arthroplasty reimbursements. To meet these changes, providers should expect qualities such as high patient volume, willingness to care for sicker patient populations, patient satisfaction, safe outcomes, and procedural demand to correlate with their reimbursement.

Clinical Relevance: Practicing orthopaedic surgeons and hospital administrators should be aware of discrepancies in inpatient reimbursement for total joint arthroplasty from Medicare. Furthermore, these discrepancies are not associated with typical economic factors. These findings warrant further investigation and collaboration between policymakers and providers to develop value-based reimbursement.

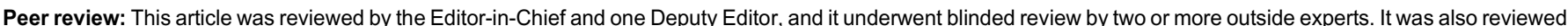

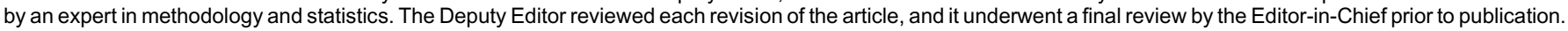
Final corrections and clarifications occurred during one or more exchanges between the author(s) and copyeditors.

$\mathrm{M}$ edicare reimbursement in total joint arthroplasty is a large part of U.S. federal health-care spending. In 2010, 1.05 million total joint arthroplasties were performed in the United States, with a total cost of approximately $\$ 20$ billion $^{1,2}$. Furthermore, the incidence of this procedure is projected to increase exponentially as the American population ages and the

Disclosure: There was no source of external funding for this study. On the Disclosure of Potential Conflicts of Interest forms, which are provided with the online version of the article, one or more of the authors checked "yes" to indicate that the author had a relevant financial relationship in the biomedical arena outside the submitted work and "yes" to indicate that the author had other relationships or activities that could be perceived to influence, or have the potential to influence, what was written in this work. 
The Journal of Bone \& Joint Surgery - jbjs.org Volume 98-A • Number $12 \cdot$ June 15, 2016
Medicare Reimbursement for Total Joint Arthroplasty: The Driving Forces
Affordable Care Act (ACA) is implemented ${ }^{3}$. An older and less healthy population undergoing total joint arthroplasty will likely require greater health-care resources because of an expected increase in complications $\mathrm{s}^{4-8}$. Additionally, the ACA should expand access to care for about $10 \%$ of the population', which should increase the demand for total joint arthroplasty ${ }^{10}$.

The ACA is taking action to cut health-care costs and to increase price transparency ${ }^{11-13}$. One specific measure enacted by the Centers for Medicare \& Medicaid Services (CMS) was the public release of inpatient charge and reimbursement data ${ }^{14}$. This makes public the mean Medicare reimbursement, inpatient charges, and provider volume for the 100 most commonly billed inpatient procedures. Although release of these data was intended to clarify health-care billing, incomplete analysis by the public media has actually made the true details of hospital reimbursement patterns more obscured ${ }^{15-18}$. The public media have focused on those physicians and hospitals at the extremes of reimbursement, shifting the focus away from what variables may actually be driving reimbursement patterns as a whole.

Given the increasing demand for total joint arthroplasty and rising costs of health care in the context of the increasing transparency of hospital reimbursement, expanded access to care, and price regulation of the $\mathrm{ACA}^{9,10}$, we attempted to analyze what variables drive Medicare reimbursement patterns. The purpose of this study was to identify geographic, socioeconomic, and healthcare quality variables that were associated with higher reimbursement for total joint arthroplasty. The time period of study is fiscal year 2011, before the implementation of the ACA. This is important because these results will provide a baseline by which we can understand how much total joint arthroplasty reimbursement will likely change after the implementation of the ACA.

\section{Materials and Methods}

This study analyzes variables associated with reimbursement to hospitals for uncomplicated primary total joint arthroplasty, diagnosis-related group (DRG) number $470^{14}$. Only providers that submitted 10 or more cases designated with DRG 470 are included in this data set, which identified 2,750 hospitals. DRG 469 , complicated primary major joint replacement, and DRGs 466 to 468 (revision arthroplasty codes) were excluded with the intention of minimizing interprocedural variability that may contribute to reimbursement variability. Reimbursement is defined by the CMS database as all payments made to the hospital for the entire stay related to DRG 470 by Medicare. Although analysis by Current Procedural Terminology (CPT) codes would have been preferable to distinguish primary hip arthroplasty from primary knee arthroplasty, the CMS only published reimbursement data by DRG in this data set. Regional analysis was performed by dividing the 2,750 providers into 306 hospital referral regions (regional level) and 1,785 hospital service areas (local level) using their operating zip code with the Dartmouth Atlas ${ }^{1920}$.

\section{Independent Variables}

The independent variables were collected from 4 sources: the United States Census Bureau $^{21} ; \mathrm{CMS}^{14}$; the Dartmouth Atlas ${ }^{19}$; and the Washington, Wyoming, Alaska, Montana, Idaho (WWAMI) Rural Health Research Center ${ }^{22}$. They were then grouped into 7 subcategories: quality, demand, supply, alternatives to total joint arthroplasty (substitutes), competitive factors, patient characteristics, and provider characteristics, as shown in the Appendix.

\section{Quality Metrics}

Given the emphasis on value-based reimbursement in the ACA, we include quality indicators in the model. Value is measured as the level of quality of care relative to the cost of care. As a result, quality of care is critical to value-based reimbursement as described in the $\mathrm{ACA}^{9}$. Data on quality of care were collected from the CMS and through the Hospital Consumer Assessment of Healthcare Providers and Systems (HCAHPS) Survey ${ }^{23,24}$. These metrics include readmission rate, complications or deaths, patient satisfaction, and surgical volume. Readmission and complication or death rates adjusted by age, sex, and comorbidities within 30 days of total joint arthroplasty were published by the CMS at the individual hospital level. Patient satisfaction assessments of each provider through the HCAHPS Survey were published by CMS at the individual hospital level. This reports the percentage of patients who gave the hospital an overall score of 9 or 10 of 10. Finally, total joint arthroplasty volume was reported in the primary CMS data set at the individual hospital level. Volume was treated as a continuous variable, and the number of patients discharged in 2011 with DRG 470 was considered a hospital's volume. We included volume as a quality measure, as it has been repeatedly shown that higher-volume surgeons and hospitals have improved outcomes ${ }^{25-29}$.

\section{Economic Drivers}

Traditional economic variables were also included in the model to explain changes in reimbursement. The Dartmouth Atlas was utilized to identify basic economic (supply and demand) variables. This data source was queried for data on the number of service providers, availability of hospital beds, and total Medicare reimbursements adjusted for age, sex, and race for each specific hospital service area $^{19}$. Provider-specific total joint arthroplasty volume was reported in the CMS data. The regional incidence of total joint arthroplasty was defined as the provider-specific volume data from the primary CMS data aggregated by hospital service area per 1,000 Medicare enrollees in the area.

The availability of alternatives to total joint arthroplasty should also affect the reimbursement. In traditional economic terms, this factor is often described as the availability of substitutes. Variables that could offer substitutes for total joint arthroplasty were identified with the Dartmouth Atlas and CMS. These included the total supply of physicians who could provide nonoperative therapy and the number of regional outpatient physical therapy offices that could provide nonoperative treatment for degenerative arthritis. Competition could also affect reimbursement for total joint arthroplasty. The amount charged for total joint arthroplasty by neighboring institutions offers insight into the local market environment. The mean charges of the neighboring hospitals were calculated for each provider and were included in the model to account for both geographic variation in reimbursement and the impact of neighboring providers' behavior. Neighboring hospitals were considered to be those within the provider's hospital referral region. Furthermore, each institution was classified as urban, large rural city or town, small rural town, or isolated small rural town using the WWAMI Rural Health Research Center data ${ }^{22}$.

\section{Patient Metrics}

Data on patient characteristics were collected using census data and were aggregated by hospital service area. The Dartmouth Atlas was utilized to determine all zip codes in each hospital service area ${ }^{19}$. The available economic characteristics for these zip codes were tabulated as weighted means by total population from the 2008 to 2012 American Community Survey ${ }^{30}$ for each hospital service area. The data from this analysis describe the general population's health insurance status, employment status, education level, overall health, and income level. The metric used to study overall health of the patient population is the hierarchical condition category, which is a score reported as hospital referral region-specific data by CMS that describes the prevalence of chronic conditions within the provider's region ${ }^{31}$. Additionally, this data set provided regional information regarding the frequency and cost of inpatient stays for Medicare beneficiaries older than 65 years of age in each hospital referral region. Finally, the proportion of beneficiaries with arthritis in each hospital referral region was also reported in this data set as a measure of disease burden for total joint arthroplasty.

\section{Provider Metrics}

The provider characteristics were taken from CMS data ${ }^{32}$. Hospital ownership was categorized into government-owned (at the state, local, or federal level), 
TABLE I The Most Clinically and Economically Relevant Variables Analyzed

\begin{tabular}{|c|c|c|}
\hline Variable & Dollars of Deviation from Mean Reimbursement* & P Value \\
\hline \multicolumn{3}{|l|}{ Quality } \\
\hline Readmission rate in percent & 105.15 & 0.147 \\
\hline Patient satisfaction in percent & -28.53 & $<0.001 \neq$ \\
\hline Volume in cases & $-1,066.08 \dagger$ & $<0.001$ 中 \\
\hline Total Medicare enrollees in cases & 0.013 & $<0.001 \neq$ \\
\hline Total joint arthroplasty per 1,000 Medicare enrollees & -73.97 & 0.351 \\
\hline \multicolumn{3}{|l|}{ Supply } \\
\hline No. of orthopaedic surgeons & 2.5 & 0.92 \\
\hline Neighbor charges & -0.02 & $<0.001$ 中 \\
\hline No. of neighboring providers & -106 & $0.001 \neq$ \\
\hline Medicare inpatient per-capita costs & 2.98 & $<0.001 \ddagger$ \\
\hline \multicolumn{3}{|l|}{ Provider characteristics } \\
\hline \multicolumn{3}{|l|}{ Provider ownership (compared with nonprofit) } \\
\hline Government & 736.86 & $<0.001 申$ \\
\hline Proprietary & -637.7 & $<0.001$ キ \\
\hline Physician & $-1,408$ & $0.001 \neq$ \\
\hline Provider charges & 0.02 & $<0.001$ キ \\
\hline
\end{tabular}

proprietarily-owned, physician-owned, voluntary nonprofit, or unknown. When computing the multivariable regression model for reimbursements, the mean provider charges were included as an independent variable.

\section{Data Analysis and Statistical Model}

The data were screened for missingness and normality. All variables were missing $<5 \%$ of data points and were mean-replaced except for the rate of readmission $(8.0 \%)$ and the rate of complication or death $(8.6 \%)$, which were $>5 \%$. The missing data for these two variables were imputed. All variables that did not have acceptable normality were log-transformed. SPSS Statistics (version 20.0; IBM) and Microsoft Excel 2013 were utilized for all statistical calculations.

The multivariable linear regression had Medicare reimbursement as the dependent variable and independent variables of quality, demand, supply, alternatives to total joint arthroplasty, competitive factors, patient characteristics, and provider characteristics. The model was run in blocks by independent variable grouping (as described above) with the previous grouping variables included in the running of the subsequent group. We report both $\mathrm{p}$ values and unstandardized coefficients $(\beta)$ that are equivalent to the dollars of deviation from mean reimbursement attributed to that variable, independently of all other variables. A greater absolute value of $\beta$ equates to a greater increase in dollars reimbursed associated independently with a unit increase of that variable.

With the release of subsequent fiscal year inpatient charges, reimbursement, and discharges for 2012 and 2013, an opportunity to investigate variation in year-to-year mean reimbursement was possible. Therefore, Pearson correla- tion of volume and reimbursement was performed. Furthermore, to validate the findings of the constructed model, reimbursement and discharge data from fiscal year 2012 (October to September) were substituted and the impact of each variable grouping was reassessed. From this analysis, it was found that total discharges billed to CMS by individual providers were highly correlated $(\mathrm{p}<0.001)$ between 2011 and $2012(\mathrm{R}=0.98)$ and between 2011 and $2013(\mathrm{R}=0.96)$. Furthermore, the mean reimbursement for major joint arthroplasty was highly correlated $(\mathrm{p}<0.001)$ between 2011 and $2012(\mathrm{R}=0.90)$ and between 2011 and $2013(\mathrm{R}=0.87)$.

\section{Results}

\section{Reimbursement Variability}

7 he CMS data set identified 427,207 total joint arthroplasties 1 performed nationally, with a weighted mean reimbursement to the hospital of $\$ 14,324.84$ (range, $\$ 9,103.27$ to $\$ 38,686.28$ ). Reimbursement variability (measured by coefficient of variation) at the national level was 0.19 . Reimbursements became less variable at the regional and local levels, with coefficients of variation of 0.12 by hospital referral region and of 0.11 by hospital service area. A map of the weighted means of Medicare reimbursements in individual hospital referral regions (Fig. 1) shows the geographic variability in Medicare reimbursement. 
Hospital Referral Region Reimbursement Percentiles
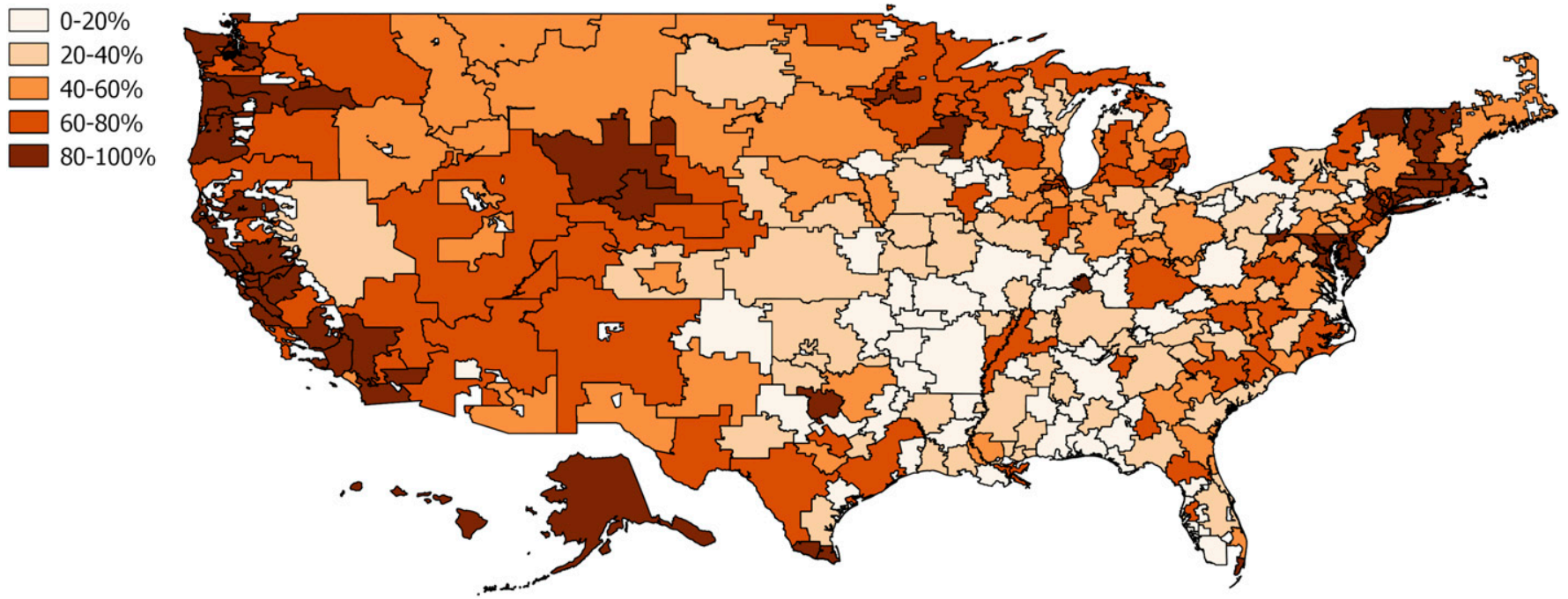

Fig. 1

A map of the United States divided into regions (hospital referral region) with weighted means of Medicare reimbursements. Regions with higher mean reimbursements appear in brown.

\section{Variables Associated with Reimbursement}

The model explained $52.5 \%\left(\mathrm{R}^{2}=0.525\right)$ of variability in reimbursement. This was validated with fiscal year 2012 data $\left(\mathrm{R}^{2}=0.557\right)$ and fiscal year 2013 data $\left(R^{2}=0.542\right)$. The largest variable groups accounting for variation were competitive factors $(12.8 \%)$, patient characteristics (10.9\%), and supply (10.0\%). Validation with fiscal

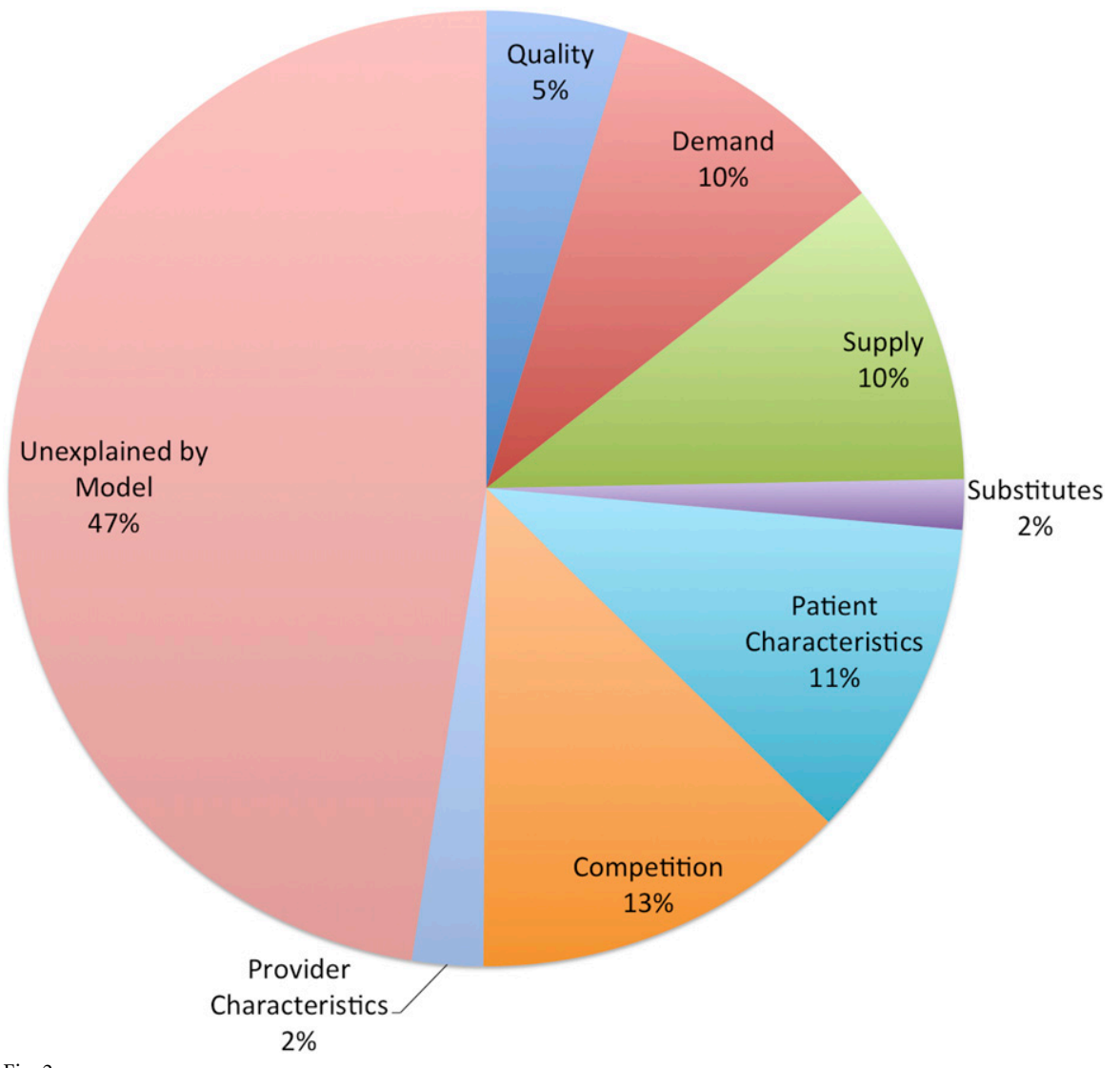

Fig. 2

Percentage of Medicare reimbursement variability explained by the predictive regression model. 
The Journal of Bone \& Joint Surgery $\cdot$ JbJs.org Volume 98-A • Number $12 \cdot$ June 15, 2016
Medicare Reimbursement for Total Joint Arthroplasty: The Driving Forces year 2012 data found that these variable groups still accounted for the most variation in reimbursement providers. Quality factors had little impact on reimbursement, accounting for only $4.8 \%$ of variability (Fig. 2). When looking at independent variables that correlated with hospital reimbursement for total joint arthroplasty, it was found that decreased patient satisfaction ( $\beta=-28.53 ; p<0.001)$, decreased provider volume (logarithmic variable, $\beta=-1,066.08 ; \mathrm{p}<0.001)$, and a more healthy patient population $(\beta=-9,208 ; \mathrm{p}<0.001)$ paradoxically correlated with increased reimbursements (Table I). Other notable variables independently associated with increased reimbursement were a lower proportion of privately insured patients $(\beta=-62.44$; $\mathrm{p}<0.001)$, government hospital ownership $(\beta=736.86 ; \mathrm{p}<$ $0.001)$, increased provider charges $(\beta=0.02 ; \mathrm{p}<0.001)$, and increased Medicare costs $(\beta=2.98 ; p<0.001)$ (Table I). Medicare reimbursements were expectedly higher with increased costs, but unexpectedly, for every dollar in increased cost, a hospital was reimbursed nearly $\$ 3$ more for that stay (\$2.98 deviation from the mean reimbursement). Each variable was examined for association with reimbursements independently of all other variables studied. The multivariable regression model does not account for whether or not these independent variables had a compounding effect when analyzed in combinations. Univariate analysis of the relationship of provider charges to Medicare reimbursement revealed a mild but significant correlation $(R=0.210$; $p<0.001)$. The Appendix contains all variables included in this model and their associated significance.

\section{Discussion}

$\mathrm{T}$ he multivariable regression model of Medicare reimbursement variability designed in this study utilized a number of variables to account for quality, demand, supply, substitutes for total joint arthroplasty, patient characteristics, competitive factors, and provider characteristics. This model explained just over half of the variation in reimbursement patterns. Notably, many of the metrics that independently correlated with increased government payment ran contrary to patterns expected from a system that rewards quality and follows basic economic principles. Quality metrics such as high patient satisfaction and patient volume $^{25-29}$ were inversely correlated with Medicare reimbursement. Hospitals that treated in regions with a sicker patient population received lower reimbursements, despite the fact that sicker patient populations typically have worse clinical outcomes with longer and more costly hospital stays and increased complications $^{4,5,8,33,34}$. Unexpectedly, government ownership of a hospital was also independently associated with higher reimbursements. Finally, more costly care was rewarded with higher reimbursements. Although we expected this result, as reimbursements account for hospital costs, the proportion of increase was unexpected. For every additional dollar of hospital cost, Medicare reimbursed \$2.98 more, a nearly threefold increase. The variables identified by this model suggest that lower cost-efficiency, lower quality, and government ownership all paradoxically correlate with higher reimbursements.

Since the release of the data set used in this study, the CMS has increased efforts to release more detailed billing in- formation. In April 2014, Medicare reimbursements were released at the individual provider level ${ }^{35}$. Following the release of these data, a number of journalists across the nation attempted to analyze these numbers for the general public ${ }^{15-18,35-37}$. The public release of this information with interpretation by the lay press has increased scrutiny on reimbursements to individual providers and institutions. However, this public analysis emphasized the outliers rather than looking at those factors that correlate with reimbursements as a whole ${ }^{15,16,18,35,36}$. Our multivariable regression model attempted to look comprehensively at the socioeconomic, quality, and efficiency variables that are really driving reimbursements. If the findings of this model are accurate, it is likely that health-care policy makers are not emphasizing quality and economic principles, as reimbursement patterns do not reflect these variables. Alternatively, if the findings that are based on these large, publicly available data sets are inaccurate, these should not be presented to the general public without more stringent analysis applied.

The major limitations of this study were a result of the source data sets. First, these data were public and therefore nonidentifiable. Consequently, individual case characteristics were unknown and may have contributed to reimbursement variability in ways not explored in this analysis. We attempted to control for this by only analyzing DRG 470. Although the proportion of patients at each institution who underwent a hip arthroplasty compared with those who underwent a knee arthroplasty was not specified by DRG 470 alone, this DRG only included primary arthroplasty (revisions are DRG 466 to 468 ) and did not include patients with a major complication or comorbidity (as delineated by DRG 469). Therefore, use of only DRG 470 should have limited a large degree of interprocedural variability. Further analysis by International Classification of Diseases, Ninth Revision (ICD-9) or CPT code might have yielded more specific results; however, these data were not available for public consumption. Additionally, the independent variables had different scopes; some variables applied to individual hospitals, some variables applied to hospital service areas, and other variables applied to hospital referral regions (as enumerated in the Appendix). The variables were used to correlate with reimbursement to individual hospitals, so the variables that applied to the hospital service area or hospital referral region may not have truly represented the nuances among different hospitals in the same region. However, different hospitals within the same catchment area should have been treating similar patient populations and should have been exposed to similar local economic climates. These differences in the scope of independent variables and lack of accounting for interprocedural variability may have accounted for at least a part of the $47.5 \%$ of reimbursement variability that was not accounted for in this model. Furthermore, analysis of this data set did not allow for comparison of those cases that may have triggered outlier flags by hospitals and may have resulted in greater reimbursement. It is possible that a hospital had a disproportionate number of outlier cases, as discussed by Li et al., requiring greater resources and therefore resulted in significantly elevated reimbursement that could not be factored 
The Journal of Bone \& Joint Surgery $\cdot$ JbjS. org Volume 98-A • Number $12 \cdot$ June 15, 2016
Medicare Reimbursement for Total Joint Arthroplasty: The Driving Forces into this analysis ${ }^{38}$. However, this should have been captured by the quality measures and the overall health (hierarchical condition category) of patients. Finally, although the independent variables selected for our model were selected with the goal of being comprehensive, there may have been other drivers of reimbursement variability that were not anticipated.

In conclusion, Medicare reimbursements for total joint arthroplasty are highly variable. Greater reimbursement was associated with lower patient volume, lower patient satisfaction, a healthier patient population, and government ownership of a hospital. There will be dramatic changes in total joint arthroplasty reimbursements as value-based reimbursement provisions of the ACA are implemented. To meet these changes, hospitals should expect qualities such as high patient volume, willingness to care for sicker patient populations, patient satisfaction, safe outcomes, and procedural demand to drive their reimbursement. It is our hope that this analysis has shed light on a complicated and controversial topic that strongly affects how the medical community is perceived by the general public.

\section{Appendix}

eA Tables showing all independent variables included in the eA multivariate regression model with their source as well as results of the multivariate regression model utilizing all variables are available with the online version of this article as a data supplement at jbjs.org.

Eric M. Padegimas, $\mathrm{MD}^{1}$

Kushagra Verma, $\mathrm{MD}^{1}$

Benjamin Zmistowski, $\mathrm{MD}^{1}$

Richard H. Rothman, $\mathrm{MD}, \mathrm{PhD}^{2}$

James J. Purtill, $\mathrm{MD}^{2}$

Michael Howley, $\mathrm{PhD}^{3}$

${ }^{1}$ Department of Orthopaedics, Thomas Jefferson University Hospital, Philadelphia, Pennsylvania

${ }^{2}$ The Rothman Institute, Thomas Jefferson University Hospital, Philadelphia, Pennsylvania

${ }^{3}$ LeBow College of Business, Drexel University, Philadelphia, Pennsylvania

E-mail address for E.M. Padegimas: padegimase@gmail.com

E-mail address for K. Verma: vermak01@gmail.com

E-mail address for B. Zmistowski: zmistowski@gmail.com

E-mail address for R.H. Rothman: rhrothman@aol.com

E-mail address for J.J. Purtill: jamespurtill@msn.com

E-mail address for M. Howley: mikehowley@drexel.edu

\section{References}

1. Rau J. Medicare identifies 97 best and 95 worst hospitals for hip and knee replacements. Kaiser Health News. 2013 Dec 17. http://www.kaiserhealthnews. org/stories/2013/december/17/medicare-best-and-worst-hospitals-for-hip-andknee-surgery.aspx. Accessed 2016 Jan 8.

2. Centers for Disease Control and Prevention (CDC). National Hospital Discharge Survey: 2010 table, number of all listed procedures from short-stay hospitals, by procedure category and age: United States, 2010. http://www.cdc.gov/nchs/data/ nhds/4procedures/2010pro4_numberprocedureage.pdf. Accessed 2016 Jan 8.

3. Kurtz S, Ong K, Lau E, Mowat F, Halpern M. Projections of primary and revision hip and knee arthroplasty in the United States from 2005 to 2030. J Bone Joint Surg Am. 2007 Apr;89(4):780-5.

4. Cram P, Lu X, Kaboli PJ, Vaughan-Sarrazin MS, Cai X, Wolf BR, Li Y. Clinical characteristics and outcomes of Medicare patients undergoing total hip arthroplasty, 1991-2008. JAMA. 2011 Apr 20;305(15):1560-7.

5. Cram P, Lu X, Kates SL, Singh JA, Li Y, Wolf BR. Total knee arthroplasty volume, utilization, and outcomes among Medicare beneficiaries, 1991-2010. JAMA. 2012 Sep 26;308(12):1227-36.

6. Pulido L, Ghanem E, Joshi A, Purtill JJ, Parvizi J. Periprosthetic joint infection: the incidence, timing, and predisposing factors. Clin Orthop Relat Res. $2008 \mathrm{Jul} ; 466$ (7):1710-5. Epub 2008 Apr 18.

7. Zmistowski B, Restrepo C, Hess J, Adibi D, Cangoz S, Parvizi J. Unplanned readmission after total joint arthroplasty: rates, reasons, and risk factors. J Bone Joint Surg Am. 2013 Oct 16;95(20):1869-76.

8. Zmistowski B, Dizdarevic I, Jacovides CL, Radcliff KE, Mraovic B, Parvizi J. Patients with uncontrolled components of metabolic syndrome have increased risk of complications following total joint arthroplasty. J Arthroplasty. 2013 Jun;28(6): 904-7. Epub 2013 Mar 21.

9. 111th United States Congress. The Patient Protection and Affordable Care Act. 2010.

10. Kinney ED. The Affordable Care Act and the Medicare program: the engines of true health reform. Yale J Health Policy Law Ethics. 2013 Summer;13(2): 253-325.

11. American Hospital Association. Achieving price transparency for consumers: a toolkit for hospitals. Community Connections. 2014 Jul. http://www. ahacommunityconnections.org/tools-resources/transparency.shtml. Accessed 2016 Jan 8.

12. Reinhardt UE. The disruptive innovation of price transparency in health care. JAMA. 2013 Nov 13;310(18):1927-8.
13. IRS. New requirements for 501 (c)(3) hospitals under the Affordable Care Act. 2015 Jun 9. http://www.irs.gov/Charities-\%26-Non-Profits/CharitableOrganizations/New-Requirements-for-501(c)(3)-Hospitals-Under-the-AffordableCare-Act. Accessed 2016 Jan 8.

14. Centers for Medicare \& Medicaid Services. Medicare provider utilization and payment data: inpatient. 2015 Jun 1. http://www.cms.gov/Research-StatisticsData-and-Systems/Statistics-Trends-and-Reports/Medicare-Provider-Charge-Data/ Inpatient.html. Accessed 2016 Jan 8.

15. Chen C, Pearson S. Top Medicare doctor paid $\$ 21$ million in 2012, data show. Bloomberg Business. 2014 Apr 9. http://www.bloomberg.com/news/articles/201404-09/top-medicare-doctor-paid-21-million-in-2012-data-shows. Accessed 2016 Jan 8. 16. Norman B. Release of Medicare pay data puts hard focus on top-billers. Politico. 2014 Apr 9. http://www.politico.com/story/2014/04/medicare-pay-data-laid-bare105500_Page2.html. Accessed 2016 Jan 8.

17. Kollipara P. Wonkbook: why doctors are upset about the Medicare payment data release. Washington Post. 2014 Apr 10. http://www.washingtonpost.com/blogs/ wonkblog/wp/2014/04/10/wonkbook-why-doctors-are-upset-about-the-medicarepayment-data-release/. Accessed 2016 Jan 8.

18. Luhby T. Doctors make millions off of Medicare. CNN. 2014 Apr 9. http:// money.cnn.com/2014/04/09/news/economy/medicare-doctors/. Accessed 2016 Jan 8.

19. The Dartmouth Institute for Health Policy and Clinical Practice. The Dartmouth Atlas of Health Care. http://www.dartmouthatlas.org/. Accessed 2016 Jan 8.

20. The Dartmouth Atlas of Health Care. Appendix A: Dartmouth Atlas regions. http://www.dartmouthatlas.org/pages/appendix_a. Accessed 2016 Jan 8.

21. United States Census Bureau. State \& county quickfacts. http://quickfacts. census.gov/qfd/states/00000.html. Accessed 2016 Jan 8.

22. Rural Health Research Center. RUCA data version 2.0. http://depts. washington.edu/uwruca/ruca-data.php. Accessed 2016 Jan 8.

23. Centers for Medicare \& Medicaid Services. Hospital outcome of care measures. https://data.medicare.gov/Hospital-Compare/Hospital-Outcome-Of-CareMeasures/rcw8-6swd. Accessed 2016 Jan 8.

24. Centers for Medicare \& Medicaid Services. Survey of patients' hospital experiences (HCAHPS). https://data.medicare.gov/Hospital-Compare/Survey-ofPatients-Hospital-Experiences-HCAHPS-/rj76-22dk. Accessed 2016 Jan 8.

25. Hervey SL, Purves HR, Guller U, Toth AP, Vail TP, Pietrobon R. Provider volume of total knee arthroplasties and patient outcomes in the HCUP-Nationwide Inpatient Sample. J Bone Joint Surg Am. 2003 Sep;85(9):1775-83. 
The Journal of Bone \& Joint Surgery $\cdot$ JBJS. Org VOlume 98-A • NUMBer $12 \cdot$ June 15, 2016
Medicare Reimbursement for Total Joint Arthroplasty: The Driving Forces
26. Kreder HJ, Deyo RA, Koepsell T, Swiontkowski MF, Kreuter W. Relationship between the volume of total hip replacements performed by providers and the rates of postoperative complications in the state of Washington. J Bone Joint Surg Am. 1997 Apr;79(4):485-94.

27. Kreder HJ, Grosso P, Williams JI, Jaglal S, Axcell T, Wal EK, Stephen DJ. Provider volume and other predictors of outcome after total knee arthroplasty: a population study in Ontario. Can J Surg. 2003 Feb;46(1):15-22.

28. Katz JN, Losina E, Barrett J, Phillips CB, Mahomed NN, Lew RA, Guadagnoli E, Harris WH, Poss R, Baron JA. Association between hospital and surgeon procedure volume and outcomes of total hip replacement in the United States Medicare population. J Bone Joint Surg Am. 2001 Nov;83(11):1622-9.

29. Katz JN, Barrett J, Mahomed NN, Baron JA, Wright RJ, Losina E. Association between hospital and surgeon procedure volume and the outcomes of total knee replacement. J Bone Joint Surg Am. 2004 Sep;86(9):1909-16.

30. United States Census Bureau. Selected economic characteristics: 2008-2012 American Community Survey 5-year estimates. http://factfinder2.census.gov/ faces/tableservices/jsf/pages/productview.xhtml?pid=ACS_12_5YR_DP03\&prodType= table. Accessed 2016 Jan 8.

31. Centers for Medicare \& Medicaid Services. Public use file: HRR table-Beneficiaries 65 and older. 2015 Oct. http://www.cms.gov/Research-Statistics-Data-and-Systems/ Statistics-Trends-and-Reports/Medicare-Geographic-Variation/GV_PUF.html. Accessed 2016 Jan 8
32. Centers for Medicare \& Medicaid Services. Hospital general information. DataMedicareGov. https://data.medicare.gov/Hospital-Compare/HospitalGeneral-Information/v287-28n3. Accessed 2016 Jan 8.

33. Jain NB, Guller U, Pietrobon R, Bond TK, Higgins LD. Comorbidities increase complication rates in patients having arthroplasty. Clin Orthop Relat Res. 2005 Jun;435:232-8.

34. Wasielewski RC, Weed H, Prezioso C, Nicholson C, Puri RD. Patient comorbidity: relationship to outcomes of total knee arthroplasty. Clin Orthop Relat Res. 1998 Nov;356:85-92.

35. U.S. Department of Health and Human Services. Press release: Historic release of data gives consumers unprecedented transparency on the medical services physicians provide and how much they are paid. 2014 Apr 9. http://www.hhs.gov/ about/news/2014/04/09/historic-release-of-data-gives-consumers-unprecedentedtransparency-on-the-medical-services-physicians-provide-and-how-much-they-are-paid.html\#. Accessed 2016 Jan 8.

36. Robles F, Lipton E. Political ties of top billers for Medicare. 2014 Apr 9. http:// www.nytimes.com/2014/04/10/business/doctor-with-big-medicare-billings-is-nostranger-to-scrutiny.html? $r=0.2014$. Accessed 2016 Jan 8.

37. Kaiser Health News. CMS releases trove of Medicare physician billing data. 2014 Apr 9. http://khn.org/morning-breakout/medicare-billing-data/. Accessed 2016 Jan 8 38. Li Y, Lu X, Wolf BR, Callaghan JJ, Cram P. Variation of Medicare payments for total knee arthroplasty. J Arthroplasty. 2013 Oct;28(9):1513-20. Epub 2013 Jul 8. 